\title{
Blood Glucose Level in Term and Preterm Newborns: A Study in Rajshahi Medical College Hospital, Rajshahi, Bangladesh
}

\author{
Rahnuma Shirin ${ }^{1 *}$, Ahmed Masiha Jamil ${ }^{2}$, Md. Belal Uddin ${ }^{3}$, Md. Shofiqul Islam ${ }^{4}$
}

\author{
${ }^{1}$ Medical Officer, Upazilla Health Complex, Mohonpur, Rajshahi, Bangladesh \\ ${ }^{2}$ Assistant Professor (Medicine), Rajshahi Medical College, Rajshahi, Bangladesh \\ ${ }^{3}$ Professor, Department of Paediatrics, Rajshahi Medical College, Rajshahi, Bangladesh \\ ${ }^{4}$ Junior Consultant, Upazilla Health Complex, Manda, Naogaon, Bangladesh
}

DOI: $10.36347 /$ sjams.2020.v08i06.020

| Received: 01.06.2020 | Accepted: 15.06.2020 | Published: 21.06.2020

*Corresponding author: Rahnuma Shirin

Abstract

Original Research Article

Glucose, amino acids and lactate are the principal energy substrates during fetal life.Hypoglycemiais one of the common metabolic hazards in neonatal medicine practice. The projected neonatal mortality rate for 2020 based on AARR from 2000-2012 is 22 per 1000 live births. It is possible that neonatal hypoglycemia arising as a consequence of fetal malnutrition, birth asphyxia, post natal hypothermia or infection could be responsible for some of unexplained neonatal death. There is an association between blood glucose level and neurological development. Our study involved 125 newbornsand blood glucose levels were estimatedat birth and at 72 hours by glucose oxidase method. A cross sectional study was conducted in Paediatrics inpatient department, Rajshahi Medical College Hospital duringfrom July-2015 to June-2017. Blood sugar levels in preterm babies were lower than term babies at birth $(63.71 \pm 15.62$ and $69.38 \pm 16.53 \mathrm{mg} / \mathrm{dl}$ respectively) where findings were not statistically significant. But findings at 72 hours were found to be statistically significant $(52.61 \pm 10.50$ and $67.10 \pm 10.11 \mathrm{mg} / \mathrm{dl})$. Incidence of hypoglycemia was $15.2 \%$.Hence forth the above study showed that hypoglycemia is a common problem in preterm babies, by taking simple low cost measures the incidence may be reduced, which may have a major impact on early infant mortality and neurodevelopmental sequel of perinatal origin.

Keywords: Hypoglycemia, Preterm, Term newborns.

Copyright @ 2020: This is an open-access article distributed under the terms of the Creative Commons Attribution license which permits unrestricted use, distribution, and reproduction in any medium for non-commercial use (NonCommercial, or CC-BY-NC) provided the original author and source are credited.

\section{INTRODUCTION}

The projected neonatal mortality rate for 2020 based on AARR from 2000-2012 is 22 per 1000 live births [1]. It is possible that neonatal hypoglycemia arising as a consequence of fetal malnutrition, birth asphyxia, post natal hypothermia or infection could be responsible for some of unexplained neonatal death [2]. During pregnancy, fetal glucose consumption increases and there is risk of maternal and possibly fetal hypoglycemia, particularly if there are long interval between meals or at night. Furthermore, premature and low birth weight babies are more susceptible to hypoglycemia since they have little adipose tissue to provide alternative fuels such as free fatty acids or ketone bodies during the transition from fetal dependency to the free living state. The enzymes of gluconeogenesis may not be functional at this time and gluconeogenesis is anyway dependent on a supply of free fatty acid for energy. Little glycerol, which would normally be released from adipose tissue, is available for gluconeogenesis [3]. The current study aims to build growing awareness of hypoglycemia in pretermbabies by comparing the blood glucose level in term and preterm babies. However, data on glycemic status of newborn is scarce in Bangladesh and other countries in Southeast Asia. I, therefore, wish to conduct this study to assess the glycemic status in low birth weight newborn and identify the relationship between hypoglycaemia and other risk factors like septicaemia, PNA, RDS, apnoea, hypothermia, convulsion and jaundice. This study will help to assess the relationship between maternal risk factors like anaemia, HTN, PET, PROM, APH and occurrance of hypoglycemia in LBW newborn. The findings of this study will help clinicians and the health policy makers to determine the strategy for improving the neonatal care programme that might eventually help to reduce the infant mortality rate in Bangladesh.

\section{Materials AND Methods}

Study Design: Cross sectional descriptive study.

Study Place: Paediatrics inpatient department, Rajshahi Medical College Hospital, Bangladesh. 
Study Period: 2 years (July-2015 to June-2017).

Study Population: The study subjects were low birth weight newborn admitted for whatever reason in paediatric inpatient department.

Sampling Procedure: Purposive sampling method.

Sample size: 125 newborns.

Sample size calculation: The sample size was estimated on the basis of a single proportion design. We assumedthat confidence interval was of $95 \%$. Taking $5 \%$ of type 1 error and precision of 5 on either side and prevalenceof $9 \%$ from previous study,

\section{Subjects and Selection Method}

The study population was drawn from consecutive 125 newborns who were delivered in Paediatrics inpatient department, Rajshahi Medical College Hospital. Samples were collected for estimation of blood glucose level at birth from umbilical cord and from cubital vein at 72 hours.

\section{Inclusion Criteria}

a) Either sex

b) Different birth weight (NBW- Normal Birth Weight, LBW- Low Birth Weight)

c) Different gestational age (Preterm or Term)

d) Different types of intrauterine growth (SGASmall for Gestational Age, AGA- Appropriate for Gestation Age)

e) Different mode of delivery (normal vaginal or caessarian section)

f) Twins

g) Duration of labor (normal or prolonged)

\section{Exclusion Criteria}

a) Newborns that suffer from

b) Congenital anomalies c) Major illness

d) Need intravenous glucose estimation

e) Die within 3 days of life

f) Neonates of mother with diabetes mellitus, gestational diabetes, preeclampsia, eclampsia, hypertension, on steroid therapy or with major illness

\section{Procedure methodology}

Written informed consent was obtained from both mother and father of the newborn. A brief clinical history was taken from mother and all the babies were examined clinically including estimation of birth weight and gestational age. Maturity of the newborns were assessed on the basis of last menstrual period of mothers and with the help of physical and neurological criteria of the baby by Expanded New ballard Scoring system. Blood samples for glucose level estimation were taken from cord blood just after birth and from cubital vein at 72 hours of life. Blood glucose levels were estimated by Glucose Oxidase method (GOD-PAP Method).

\section{Statistical analysis}

Data was analysed using SPSS version 20.0 (SPSS Inc., Chicago, IL). Analysis was performed by using t-test. For comparison of the mean values ANOVA test was used. $\mathrm{P}<0.05$ was considered significant.

\section{RESULTS}

The study population was drawn from consecutive 125 newborns who were delivered in Paediatrics inpatient department, Rajshahi Medical College Hospital, Bangladesh. Samples were collected for estimation of blood glucose level at birth from umbilical cord and from cubital vein at 72 hours. Shows the total number of newborns studied. Male babies were more than female babies (Figure-1).

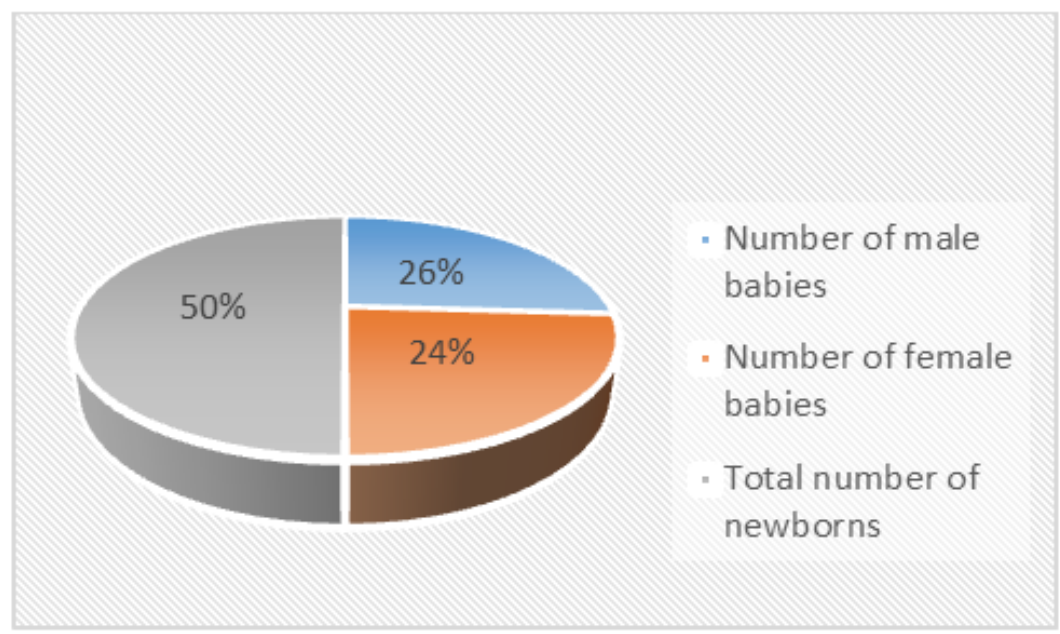

Fig-1: Distribution of male and female newborns 
Table-1 shows that the blood sugar levels in low birth weight babies were lower than that of normal birth weight babies both at birth and 72 hours of age.
But, no statistically significant correlation was found between values of these groups at birth $(\mathrm{p}=0.10)$ and at 72 hours of life $(\mathrm{p}>0.10)$.

Table-1: Distribution of blood sugar level in low birth weight and normal birth weight newborn babies

\begin{tabular}{|c|c|c|c|c|c|c|}
\hline \multirow{2}{*}{ Groups } & \multirow[t]{2}{*}{ Age of baby } & \multirow[t]{2}{*}{ No of cases } & \multicolumn{2}{|c|}{ Blood sugar(mg/dl) } & \multirow[t]{2}{*}{ SD } & \multirow[t]{2}{*}{$\mathbf{S E}$} \\
\hline & & & Range & Mean & & \\
\hline Low Birth & Birth & 43 & $30-100$ & 65.32 & 14.00 & 2.13 \\
\hline Weight & 72 hours & 43 & $25-94$ & 62.88 & 14.44 & 2.20 \\
\hline Normal Birth & Birth & 82 & $37-145$ & 72.06 & 17.45 & 1.92 \\
\hline Weight & 72 hours & 82 & $43-95$ & 65.60 & 9.74 & 1.07 \\
\hline
\end{tabular}

Table-2 shows that the blood sugar level in preterm babies were lower than that of term babies at birth but no statistically significant correlation $(p>0.10)$ was found. At 72 hours of age, blood sugar levels in term babies were much higher than preterm babies and were highly significant statistically $(\mathrm{p}<0.01)$.

Table-2: Distribution of blood sugar level in preterm (babies with gestation age $<37$ weeks and term babies with gestation age $\geq 37$ weeks)

\begin{tabular}{|l|l|l|l|l|l|l|}
\hline Groups & Age of baby & \multirow{2}{*}{ No of cases } & \multicolumn{2}{|l|}{ Blood sugar(mg/dl) } & SD & SE \\
\cline { 4 - 5 } & & & Range & Mean & & \\
\hline Preterm babies & Birth & 21 & $30-91$ & 63.71 & 15.62 & 3.41 \\
\cline { 2 - 7 } & 72 hours & 21 & $25-88$ & 52.61 & 10.50 & 2.29 \\
\hline \multirow{2}{*}{ Term babies } & Birth & 104 & $37-145$ & 69.38 & 16.53 & 1.62 \\
\cline { 2 - 7 } & 72 hours & 104 & $43-93$ & 67.10 & 10.11 & 0.99 \\
\hline
\end{tabular}

Table-3 shows that the blood sugar level in AGA babies were higher than that of SGA babies at birth and values were statistically significant $(\mathrm{p}<0.02)$.
But no statistical correlation was found between the values of these two groups at 72 hours $(p>0.10)$.

Table-3: Distribution of blood sugar level in small for gestational age (SGA) and appropriate for gestational age (AGA) newborn babies

\begin{tabular}{|l|l|l|l|l|l|l|}
\hline Groups & Age of baby & \multirow{2}{*}{ No of cases } & \multicolumn{2}{|l|}{ Blood sugar(mg/dl) } & SD & SE \\
\cline { 4 - 6 } & & & Range & Mean & & \\
\hline SGA babies & Birth & 26 & $30-95$ & 61.80 & 13.25 & 2.65 \\
\hline & 72 hours & 26 & $36-94$ & 63.03 & 14.21 & 2.84 \\
\hline AGA babies & Birth & 99 & $33-145$ & 69.41 & 16.70 & 1.68 \\
\hline & 72 hours & 99 & $25-95$ & 64.43 & 11.26 & 1.13 \\
\hline
\end{tabular}

Table-4 shows that at birth blood sugar level of babies delivered normally were lower than the babies delivered by caessarian section and were statistically highly significant $(\mathrm{p}<0.01)$. Blood sugar levels of normally delivered babies were increased from birth to
72 hours of age but that of caessarian babies were decreased. However, no statistically significant correlation was found between the values of these two groups at 72 hours $(\mathrm{p}>0.10)$.

Table-4: Distribution of blood sugar level in newborn delivered normally (vaginal delivery) and in babies delivered by caessarian section (C.S.)

\begin{tabular}{|l|l|l|l|l|l|l|}
\hline \multirow{2}{*}{ Groups } & Age of baby & \multirow{2}{*}{ No of cases } & \multicolumn{2}{|l|}{ Blood sugar(mg/dl) } & SD & SE \\
\cline { 3 - 7 } & & & Range & Mean & & \\
\hline \multirow{2}{*}{$\begin{array}{l}\text { Babies delivered } \\
\text { normally }\end{array}$} & Birth & 71 & $30-145$ & 63.76 & 16.46 & 1.95 \\
\cline { 2 - 7 } & 72 hours & 71 & $39-95$ & 64.43 & 12.33 & 1.46 \\
\hline \multirow{2}{*}{$\begin{array}{l}\text { Babies delivered } \\
\text { by C.S. }\end{array}$} & Birth & 54 & $43-103$ & 74.57 & 14.43 & 1.96 \\
\cline { 2 - 6 } & 72 hours & 54 & $25-92$ & 64.98 & 10.70 & 1.45 \\
\hline
\end{tabular}

Table-5 shows that blood sugar levels in babies delivered following normal labor were lower than babies delivered after prolonged labor at birth but there was no statistical correlation ( $p>0.10)$. At 72 hours of age blood sugar levels in babies delivered following normal labor were also lower than babies delivered after prolonged labor which is also not significant statistically $(p>0.10)$. But in prolonged labor, there is significant increase in blood sugar levels $(\mathrm{p}<0.01)$. 
Table-5: Distribution of blood sugar level in babies in relation to normal and prolonged labor

\begin{tabular}{|l|l|l|l|l|l|l|}
\hline Groups & Age of baby & \multirow{2}{*}{ No of cases } & \multicolumn{2}{|l|}{ Blood sugar(mg/dl) } & SD & SE \\
\cline { 3 - 7 } & & & Range & Mean & & \\
\hline \multirow{2}{*}{ Normal labor } & Birth & 104 & $37-145$ & 65.43 & 20.73 & 2.03 \\
\cline { 2 - 7 } & 72 hours & 104 & $36-149$ & 72.45 & 20.61 & 2.21 \\
\hline \multirow{2}{*}{ Prolonged labor } & Birth & 21 & $25-88$ & 69.43 & 19.93 & 4.34 \\
\cline { 2 - 7 } & 72 hours & 21 & $35-103$ & 76.79 & 24.91 & 5.43 \\
\hline
\end{tabular}

Table-6 shows that blood sugar level in first baby were higher than second baby at birth but there was no statistically significant correlation $(\mathrm{p}>0.10)$. At
72 hours of age blood sugar levels in first baby were also higher than second baby of twin and also not significant statistically $(\mathrm{p}>0.10)$.

Table-6: Blood sugar level in the first baby and second baby in twin delivery

\begin{tabular}{|l|l|l|l|l|l|l|}
\hline \multirow{2}{*}{ Groups } & Age of baby & \multirow{2}{*}{ No of cases } & \multicolumn{2}{|l|}{ Blood sugar(mg/dl) } & SD & \multirow{2}{*}{ SE } \\
\cline { 3 - 5 } & & & Range & Mean & & \\
\hline \multirow{2}{*}{ First baby } & Birth & 05 & $30-100$ & 63.37 & 7.89 & 3.53 \\
\cline { 2 - 6 } & 72 hours & 05 & $36-122$ & 72.36 & 8.75 & 3.91 \\
\hline \multirow{2}{*}{ Second baby } & Birth & 05 & $25-94$ & 57.11 & 7.39 & 3.30 \\
\cline { 2 - 5 } & 72 hours & 05 & $43-95$ & 65.60 & 9.74 & 4.35 \\
\hline
\end{tabular}

Table-7 shows that maximum incidence of hypoglycemia occurred within 24 hours of age.

Table-7: Incidence of hypoglycemia in relation to the age of newborns

\begin{tabular}{|l|l|l|l|}
\hline Age of newborns in hours & $\mathbf{0 - 2 4} \mathbf{~ h r s}$ & $\mathbf{2 4 - 4 8} \mathbf{~ h r s}$ & $\mathbf{4 8 - 7 2}$ hrs \\
\hline Number of hypoglycemic cases & 12 & 4 & 3 \\
\hline Percentage of hypoglycemic cases & 63.15 & 21.05 & 15.78 \\
\hline
\end{tabular}

Table- 8 shows that hypoglycemia appeared in 19 babies.

Table-8: Incidence of hypoglycemia

\begin{tabular}{|l|l|}
\hline Total number of cases under study & $\mathbf{1 2 5}$ \\
\hline Number of hypoglycemic cases & 19 \\
\hline Percentage & 15.20 \\
\hline
\end{tabular}

Table-9 shows that 19 babies developed hypoglycemia and 9 babies were symptomatic.

Table-9: Total number of symptomatic hypoglycemic cases

\begin{tabular}{|l|l|}
\hline Total number of cases under study & $\mathbf{1 2 5}$ \\
\hline Number of hypoglycemic cases & $19(15.20 \%)$ \\
\hline Total symptomatic hypoglycemic cases & $9(7.2 \%)$ \\
\hline
\end{tabular}

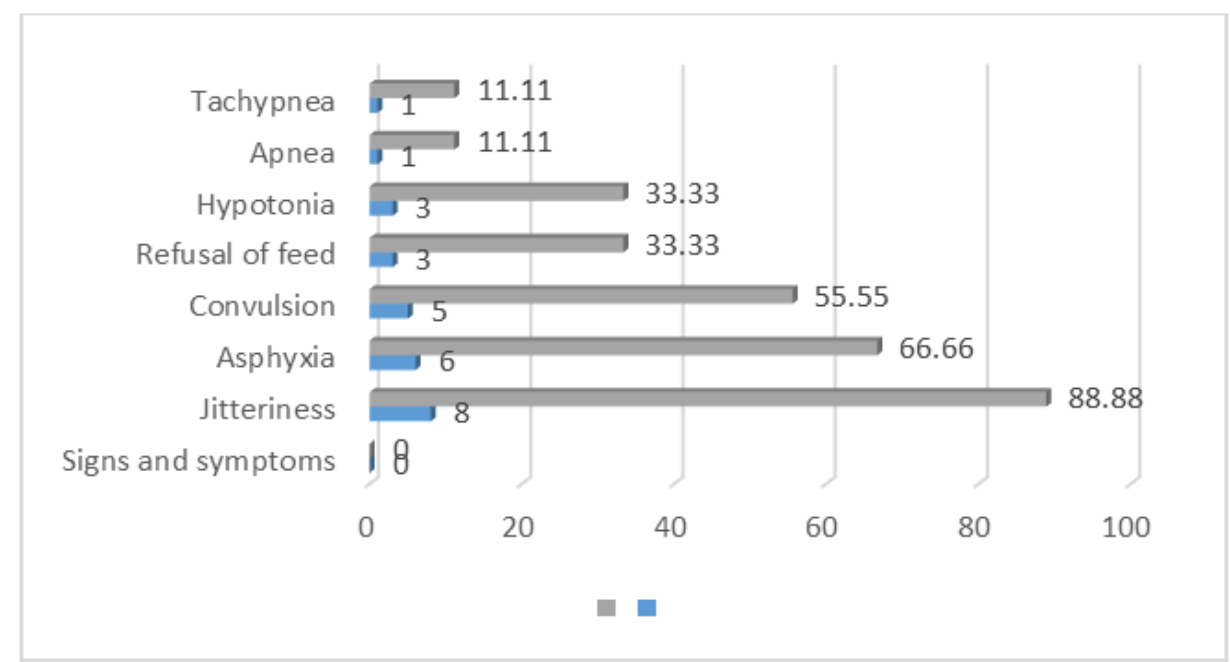

Fig-2: Signs and symptoms observed in symptomatic hypoglycemic newborns 
Figure-2 shows that out of 9 symptomatic cases, 8 babies had jitteriness, 6 babies had asphyxia, 5 babies had convulsion, 3 babies had refusal of feed as well as hypotonia and 1 baby had apnea and tachypnea.

\section{DISCUSSION}

Hypoglycemia is one of the most frequent metabolic problems in neonatal period. It is not a disease but a symptom of other diseases or lack of metabolic adaptation postnatally. Menifestations of hypoglycemia are non-specific. Hypoglycemia is often unexplained by other diagnoses and corrected with the provision of glucose. The male-female birth ratio of the population for India is $1.06 .{ }^{4}$ In the present study, malefemale birth ratio is 1.082 in this north-east region of this country which shows slight increase. Miranda LE and Dweck HS [5] stated that very low birth weight babies have the potential problem of hypoglycemia due to diminished hepatic glycogen stores.In present study, blood sugar levels in low birth weight babies were lower than normal birth weight babies both at birth and 72 hours. But no statistically significant correlation was found between values of these two groups at birth and at 72 hours of life.Preterm babies had a group mean value of $39.8 \mathrm{mg} \%$ as compared to $47.2 \mathrm{mg} \%$ in term babies, as described by Bhalla M et al., [6]. In this study also blood sugar level in preterm babies (mean 63.71 $\mathrm{mg} / \mathrm{dl}$ ) were lower than term babies (mean $69.38 \mathrm{mg} / \mathrm{dl}$ ) at birth and at $72 \mathrm{hrs}$ of age blood sugar levels in term babies (mean $67.10 \mathrm{mg} / \mathrm{dl}$ were much higher than preterm babies (mean $52.61 \mathrm{mg} / \mathrm{dl}$ ). In a study by Linda LW et al., [7] plasma glucose levels were measured during the first day of life in 24 SGA infants who began formula feedings or breast milk feeding within 2 hours of birth. In contrast to the high incidence of low blood sugar seen previously in fasted SGA infants, no infant had a plasma glucose below $30 \mathrm{mg} / \mathrm{dl}$; after the first feeding, no values below $40 \mathrm{mg} / \mathrm{dl}$ occurred. The results indicate that hypoglycemia (plasma glucose $<40 \mathrm{mg} / \mathrm{dl}$ ) can be easily avoided in SGA infants simply by providing adequate calories without delay after delivery.In present study, blood glucose levels in AGA babies were higher than SGA babies at birth and even at 72 hours. And hypoglycemia appeared in 6 cases of SGA babies and 13 cases of AGA babies. This study indicates the role of early feeding to prevent subsequent hypoglycemia which is similar with their study. Cole MD and Peevy K [8] disclosed a $43 \%$ incidence of hypoglycemia in neonates delivered by caessarian section and a $37 \%$ incidence in neonates delivered vaginally.In this study, distribution of blood sugar level in babies delivered normally (vaginal delivery) and in babies delivered by caessarian section showed that at birth blood sugar level of babies delivered normally (mean $63.76 \mathrm{mg} / \mathrm{dl}$ ) were lower than babies delivered by caessarian section (mean $74.57 \mathrm{mg} / \mathrm{dl}$ ) and were statistically significant. Blood sugar level of normally delivered babies increased from birth to $72 \mathrm{hrs}$ of age but that of caessarian babies decreased. However, no statistically significant correlation was found between the values (mean $64.43 \mathrm{mg} / \mathrm{dl}$ in normally delivered babies vs. $64.98 \mathrm{mg} / \mathrm{dl}$ in caessarian babies) of these two groups at $72 \mathrm{hrs}$. Hypoglycemia appeared in 5 cases $(7.04 \%)$ of babies delivered normally and 14 cases (25.92\%) of babies delivered by caessarian section. Kim $\mathrm{G}$ and Chul Y [9] evaluated the blood glucose of the mother and fetus in relation to length of labor. They found that the glucose level in the blood of the mother was unchanged by the duration of labor. However, the glucose level in the blood of the fetus had a tendency to rise upto 20 hours and decreased after this time.In this study, blood sugar level in babies delivered following normal labor (mean $65.43 \mathrm{mg} / \mathrm{dl}$ ) were lower than babies delivered after prolonged labor (mean 69.43 $\mathrm{mg} / \mathrm{dl}$ ) at birth but there was no statistically significant correlation. At 72 hours of age, blood sugar levels in babies delivered following normal labor were lower than babies delivered after prolonged labor. But that is also not statistically significant. This study shows that in prolonged labor, blood glucose level increases significantly from birth to $72 \mathrm{hrs}$. This result contradicts with their observation and probably due to stress to the newborn during prolonged labor.Mishra PK et al., [10] observed that blood sugar levels had a definite correlation with birth weight and gestational age, significantly higher values were observed in infants weighing $2250 \mathrm{gm}$ and also infants having a gestational age of over 37 weeks. The mean sugar values did not differ between the larger and smaller twin, nor were the values influenced by birth order or sex of these infants. Significant hypoglycemia (blood sugar $<20 \mathrm{mg} \%$ ) was observed in smaller member of the twin $(70 \%)$ in 7 infant.Present study shows that blood sugar level in first baby (mean $63.37 \mathrm{mg} / \mathrm{dl}$ ) were higher than second baby (mean $57.22 \mathrm{mg} / \mathrm{dl}$ ) (more in larger baby than smaller babies) at birth but there was no statistically significant correlation. At $72 \mathrm{hrs}$ of age, blood sugar levels in first baby (mean $72.36 \mathrm{mg} / \mathrm{dl}$ ) were also higher than second baby of twin (mean $65.60 \mathrm{mg} / \mathrm{dl}$ ) were also higher than second baby of twin (mean $65.60 \mathrm{mg} / \mathrm{dl}$ ) and also not significant statistically. The results were similar with their observations.Prevalence of hypoglycemia ranges from $5 \%$ to $7.9 \%$ for term infants and $3.5 \%$ to $15 \%$ in preterm infants, as described by Cornblath $\mathrm{M}$ and Schwartz R [11]. In present study, hypoglycemia developed in 19 cases $(15.20 \%)$ of study group.In a study by Fato $\mathrm{T}$ et al., [12] glucose levels were measured in all 35 newborns at the $1^{\text {st }}, 2^{\text {nd }}, 3^{\text {rd }}$ hr and 14 , 24, 36 and 48 hrs before feeding. The lowest blood glucose level was seen in the first $3 \mathrm{hrs}$ of life. In the first $3 \mathrm{hrs}$ of life there were 12 infants with glucose levels less than $30 \mathrm{mg} / \mathrm{dl}$ but in only three of those did the hypoglycemic level continue and require treatment $(9 \%)$. In present study, maximum incidence of hypoglycemia $(63.15 \%)$ occurred within $24 \mathrm{hrs} .21 .05 \%$ between 24 to $48 \mathrm{hrs}$. Remaining $15.78 \%$ of cases between 48-72 hrs of age. This study indicates the role of early feeding to prevent subsequent hypoglycemia which is similar with the finding of Holtrop PC [13] and Fato $\mathrm{T}$ et al., [12] but contradict the finding of Linda 
LW et al., [7], Lucas A et al., [14] stated that symptomatic hypoglycemia is associated with a risk of long-term neurodevelopmental sequel because of metabolic immaturity. They observed that preterm infants and infants that are small for gestational age were at greater risk of sequel. In a study by Koivisto M et al., [15] among 85 infants who had suffered symptomatic hypoglycemia, only $50 \%$ presented with convulsions and $88 \%$ of those with non-convulsive symptoms were developmentally normal.In the present study out of 19 cases only $9(47.36 \%)$ were symptomatic. Out of symptomatic babies, $8(88.88 \%)$ had jitteriness, $6(66.6 \%)$ had asphyxia, 5 (55.55\%) had convulsion, $3(33.33 \%)$ had hypotonia as well as refusal of feed and $1(11.11 \%)$ had apnea and tachypnea.

\section{Conclusion}

To prevent the sequels of hypoglycemia, determination of blood sugar of newborns before the development of clinical sign and symptom is recommended.

\section{REFERENCES}

1. Sankar MJ, Neogi SB, Sharma J, Chauhan M, Srivastava R, Prabhakar PK, Khera A, Kumar R, Zodpey S, Paul VK. State of newborn health in India. Journal of Perinatology. 2016 Dec;36(3):S38.

2. Ashworth A, Waterlow JC. Infant mortality in developing countries. Arch Dis child, 1982; 57:882-4.

3. David AB, Peter AM. Gluconeogenesis and control of blood glucose. In: Murray RK, Granner DK, Rodwell VW, editors. Harper'sIllustrated Biochemistry. 27 $7^{\text {th }}$ Ed. New York: McGraw-Hill; 2006. 167-76.

4. India Guide: Population of India. Sex ratio in India 2018.

Available http://ww.indiaonlinepages.com/population/sexratio-of india.html. Accessed November 21, 2018.

5. Miranda LE, Dweck HS. Perinatal glucose homeostasis: the unique character of hyperglycemia and hypoglycemia in infants of very low birth weight. ClinPerinatol, 1977; 4:35165.

6. Bhalla M, Sribastava JR, Bhalla JN, Sinha DN, Sur BK. A study of blood glucose level in the newborn-from birth to 7 days. Indian J Pediatr, 1978; 45:11-7.

7. Linda LW, Charles AS, Endla KA, Lester B. The effect of early feeding on plasma glucose levels in SGA infants. Clinpediatr, 1983; 22(8):539-41.

8. Cole MD, Peevy K. Hypoglycemia in normal neonates appropriate for gestational age. J Perinatol, 1994; 14:118-20.

9. Kim G, Chul Y. The maternal and fetal glucose levels during labor. Korean Medical Database, 1970; 13(1):15-21.

10. Mishra PK, Sethi RS, Sharrma D. Blood sugar level in twin neonate. Indian J Pediatr, 1984; 51:661-3.

11. Cornblath M, Schwartz R. Hypoglycemia in the neonate. J PediatrEndocrinol, 1993; 6:113-29.

12. Fato T, Nursel Y, Hidayet Y, Dilara I. Blood glucose levels and hypoglycemia in full term neonates during the first 48 hours of life. J Trop Pediatr, 1997; 43(1):58-60.

13. Holtrop PC. The frequency of hypoglycemia in full-term large and small for gestational age newborns. Am J Perinatol, 1993; 10:150-4.

14. Lucas A, Morley R, Cole TJ. Adverse neurodevelopmental outcome of moderate neonatal hypoglycemia. $\mathrm{Br}$ Med J, 1988; 297:1304-8.

15. Koivisto $\mathrm{M}$, Blancosequeiros $\mathrm{M}$, Krause $\mathrm{U}$. Neonatal symptomatic and asymptomatic hypoglycemia: a follow-up study. Dev Med Child Neurol, 1972; 14:603-14. 